\title{
On the extraction of wind information from the assimilation of ozone profiles in Météo-France 4-D-Var operational NWP suite
}

\author{
N. Semane ${ }^{1,2}$, V.-H. Peuch ${ }^{1}$, S. Pradier ${ }^{1}$, G. Desroziers ${ }^{1}$, L. El Amraoui ${ }^{1}$, P. Brousseau ${ }^{1}$, S. Massart ${ }^{3}$, B. Chapnik ${ }^{1}$, and \\ A. Peuch ${ }^{4}$ \\ ${ }^{1}$ CNRM-GAME, Météo-France and CNRS URA 1357, Toulouse, France \\ ${ }^{2}$ CNRM, Direction de la Météorologie Nationale, Casablanca, Morocco \\ ${ }^{3}$ CERFACS, Toulouse, France \\ ${ }^{4}$ DP, Météo-France, Toulouse, France
}

Received: 24 June 2008 - Published in Atmos. Chem. Phys. Discuss.: 28 August 2008

Revised: 2 July 2009 - Accepted: 10 July 2009 - Published: 22 July 2009

\begin{abstract}
By applying four-dimensional variational dataassimilation (4-D-Var) to a combined ozone and dynamics Numerical Weather Prediction model (NWP), ozone observations generate wind increments through the ozonedynamics coupling. The dynamical impact of Aura/MLS satellite ozone profiles is investigated using Météo-France operational ARPEGE NWP 4-D-Var assimilation system for a period of 3 months. A data-assimilation procedure has been designed and run on 6-h windows. The procedure includes: (1) 4-D-Var assimilating both ozone and operational NWP standard observations, (2) ARPEGE transporting ozone as a passive-tracer, (3) MOCAGE, the Météo-France chemistry and transport model re-initializing the ARPEGE ozone background at the beginning time of the assimilation window. Using observation minus forecast statistics, it is found that the ozone assimilation reduces the wind bias in the lower stratosphere. Moreover, the Degrees of Freedom for Signal diagnostics show that the MLS data covering the 68.1$31.6 \mathrm{hPa}$ vertical pressure range are the most informative and their information content is nearly of the same order as tropospheric humidity-sensitive radiances. Furthermore, with the help of error variance reduction diagnostics, the ozone contribution to the reduction of the horizontal divergence background-error variance is shown to be better than tropospheric humidity-sensitive radiances.
\end{abstract}

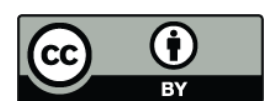

Correspondence to: N. Semane (semane@cnrm.meteo.fr)

\section{Introduction}

Over the years, data assimilation schemes have evolved into very sophisticated systems, such as four-dimensional variational 4-D-Var (Rabier et al., 2000), which is operational in the numerical weather prediction (NWP) system of MétéFrance, ARPEGE. The scheme combines a large variety of both space- and surface-based meteorological observations with background information of the atmospheric state. During the 4-D-Var process, the evolution of the linearized forecast model and its adjoint act as an additional constraint (Andersson et al., 1994).

Ozone is a radiatively important atmospheric trace gas and 4-D-Var is adapted to produce four-dimensional ozone analyses consistent with atmospheric dynamics, e.g.: (i) assimilation of ozone observations in a modern four-dimensional variational data assimilation (4-D-VAR) will have a direct impact on the wind field (Eskes et al., 2005); (ii) in chemistry-transport model (CTM) studies, the ECMWF 4D-Var operational analyses have been seen to produce better age-of-air values (Geer et al., 2006); (iii) because 4-D-Var includes the time dimension, the temporal discrepancy between the initial state is accounted for (Lahoz et al., 2007). The assimilation of ozone can have a beneficial impact on the dynamics forecast modeling. Ozone influences the model temperature through the radiation parametrization, often referred to as "ozone/radiation interaction" (Cariolle and Morcrette, 2006). Moreover, an accurate ozone knowledge may improve the use of satellite radiances sensitive to ozone such as long-wave channels of both the High Infrared Resolution Sounder HIRS (e.g., Derber and Wu, 1998) and the

Published by Copernicus Publications on behalf of the European Geosciences Union. 
Advanced Microwave Sounder AMSU-B (e.g., John and Buehler, 2004). In addition to these potential benefits, 4-DVar ozone assimilation can improve the wind field through dynamics-ozone coupling. This takes advantage of the fact that the photochemical lifetime of ozone is relatively long in the upper troposphere-lower stratosphere (UTLS) region where vertical and horizontal motions associated with synoptic scales systems lead to similar ozone and isentropic potential vorticity (IPV) anomalies (Reed, 1950; Danielsen, 1968; Davis et al., 1999; Semane et al., 2002). This could bring a valuable correction of model uncertainties in the UTLS region. Daley (1995) highlighted the feasibility of inferring dynamical information on wind fields from the assimilation of chemical constituent observations, given sufficiently dense, frequent and accurate measurements. Riishøjgaard (1996) demonstrated the use of ozone measurements to reconstruct the flow field in a barotropic vorticity equation model. The study of Holm et al. (1999) showed in detail the wind-ozone coupling in a 4-D-Var system. Peuch et al. (2000) demonstrated the dynamical impact of total ozone column observations in Observing System Simulation Experiments (OSSEs) using the ARPEGE 4-D-Var suite. All studies agree that two prerequisites for producing a beneficial interaction between the ozone and wind fields within 4-D-Var are the use of high quality observations and background ozone fields. These have proven to be very strong constraints and, up to now, few results obtained with actual ozone observations have been presented. In this work, the dynamical impact of ozone 4D-Var assimilation is thus investigated within a framework in which ARPEGE is run during a period of 3 months from 23 January to 22 April 2006 with the following input:

- Frequent and accurate UTLS ozone profiles from the Microwave Limb Sounder (MLS) aboard the Aura satellite with a vertical resolution of $2.7 \mathrm{~km}$ in the UTLS and a horizontal resolution of $165 \mathrm{~km}$ (Waters et al., 2006).

- Ozone background provided by MOCAGE, a comprehensive chemistry and transport model (CTM) of Météo-France (Peuch et al., 1999). This background is consistent with dynamical fields of ARPEGE as MOCAGE is driven by ARPEGE dynamics.

The observation minus forecast (OMF) statistics are used to examine how the wind fields are affected by the assimilation of MLS data. In addition, the information content of MLS data is examined by using the Degrees of Freedom for Signal diagnostics. With the help of the error variance reduction diagnostic of Desroziers et al. (2005), the reduction of the initial background error variance of wind fields due to MLS ozone data assimilation is also described. The results are compared to humidity-sensitive radiances of HIRS and AMSU-B sounders. The paper is outlined as follows: Sect. 2 presents the MLS ozone assimilation procedure, Sect. 3 describes the dynamical impact of ozone data, and Sect. 4 summarizes the results and discusses their implication.

\section{MLS ozone assimilation procedure}

Thanks to the 4-D-Var assimilation process, ozone observations affect not only the analysis of the ozone field itself, but also the analysis of the wind field through the adjoint of the ozone advection model. In this study, the 4-D-Var ozonewind relationship within the assimilation window is, thus, investigated in an univariate approach in which the wind and ozone are only coupled via the tracer transport equation and not via the background error covariances. According to Peuch et al. (2000), ozone observations will improve the wind field only if they are sufficiently accurate and numerous, if the linearized ozone advection model is appropriate for simulating time-space evolution over the assimilation window and finally if the background is consistent with the observations. The 4-D-Var experiment carried out in this study attempts to meet these requirements as closely as possible through the use of MLS observations and ozone background derived from the MOCAGE CTM at the beginning of each 4-D-Var ARPEGE data-assimilation cycle.

\subsection{MLS measurements}

The Aura satellite was launched on 15 July 2004 and placed into a near-polar Earth orbit at $\sim 705 \mathrm{~km}$. It orbits the Earth around 14 times per day. The MLS instrument aboard Aura uses the microwave limb sounding technique to measure chemical constituents between the upper troposphere and the lower mesosphere. It is an advanced version of the MLS instrument on the Upper Atmosphere Research Satellite (UARS). This is because it provides more dense spatial coverage with its daily 3500 profiles, between $82^{\circ} \mathrm{N}$ and $82^{\circ} \mathrm{S}$, while UARS MLS could only produce up to $1300 \mathrm{ev}-$ ery day. In addition, Aura MLS ozone profiles are retrieved with a horizontal resolution of $165 \mathrm{~km}$ and a typical vertical resolution of about $2.7 \mathrm{~km}$ in the stratosphere (Froidevaux et al., 2006; Jackson, 2007; Stajner et al., 2008; Feng et al., 2008). Although Aura MLS observations contain useful information on ozone concentrations between $316 \mathrm{hPa}$ and $0.1 \mathrm{hPa}$, only the data between 215.4 and $0.46 \mathrm{hPa}$ are recommended for scientific research. Precision is around 20-50 ppbv (parts per billion by volume) and $0.1-0.2 \mathrm{ppmv}$ (parts per million by volume) in the vertical ranges 215.4$22 \mathrm{hPa}$ and $21.5-0.46 \mathrm{hPa}$, respectively (Waters et al., 2006). In this study, the first publicly available Aura MLS dataset, version 1.5, of ozone profiles from 23 January to 22 April 2006, is used. As high biases exist at $215.4 \mathrm{hPa}$ for equatorial latitudes, data for this level covering the $30^{\circ} \mathrm{N}-30^{\circ} \mathrm{S}$ latitude range are discarded. The observational error in the used data-assimilation experiment is prescribed directly from the precision estimate supplied with the Aura MLS data; no bias correction is applied. 


\subsection{MOCAGE model}

MOCAGE (MOdèle de Chimie Atmosphérique à Grande Echelle) is a three-dimensional chemistry transport model of the troposphere and stratosphere. It provides a number of optional configurations with varying domain geometries and resolutions, as well as chemical and physical parametrization packages. It is used for operational chemical weather prediction (e.g., Dufour et al., 2004; Hollingsworth et al., 2008; Rouil et al., 2009) and chemical data assimilation research (e.g., Semane et al., 2007; Massart et al., 2007; El Amraoui et al., 2008a, 2008b). The transport scheme of MOCAGE is semi-lagrangian (Rasch and Williamson, 1990) and the chemical one used in this study is the comprehensive scheme RACMOBUS, which combines the stratospheric scheme REPROBUS (Lefèvre et al., 1994) and the tropospheric scheme RACM (Stockwell et al., 1997). MOCAGE is forced by external wind and temperature fields from the operational meteorological model of Météo-France, ARPEGE (Courtier et al., 1991) and is used with its global horizontal resolution of $2^{\circ}$ both in latitude and longitude, including 47 hybrid levels from the surface up to $5 \mathrm{hPa}$. The vertical resolution is about $800 \mathrm{~m}$ in the vicinity of the tropopause and in the lower stratosphere.

\subsection{Assimilation methodology}

The notation in this paper will follow Ide et al. (1997) as closely as possible. Météo-France uses the 4-D-Var scheme as part of its ARPEGE NWP system (Rabier et al., 2000). This scheme minimizes the following function $J(\delta \boldsymbol{x})$ :

$J(\delta x)=J_{b}(\delta x)+J_{o}(\delta x)+J_{c}(\delta x)$

where the increment vector $\delta \boldsymbol{x}$ is the difference between the model state $\boldsymbol{x}$ and the background state $\boldsymbol{x}^{b}$. The $J_{b}(\boldsymbol{\delta} \boldsymbol{x})$ term in Eq. (1) refers to the background cost function

$J_{b}(\delta \boldsymbol{x})=\delta \boldsymbol{x}^{T} \mathbf{B}^{-1} \boldsymbol{\delta} \boldsymbol{x}$

and the $J_{o}(\boldsymbol{\delta} \boldsymbol{x})$ term refers to the observation cost function

$J_{o}(\boldsymbol{\delta} \boldsymbol{x})=(\mathbf{d}-\mathbf{H}(\boldsymbol{\delta} \boldsymbol{x}))^{T} \mathbf{R}^{-1}(\mathbf{d}-\mathbf{H}(\boldsymbol{\delta} \boldsymbol{x}))$

where $\boldsymbol{d}=\boldsymbol{y}^{\circ}-\mathcal{H}\left(\boldsymbol{x}_{b}\right)$ is the departure between the observation vector $\boldsymbol{y}^{\circ}$ and its model equivalent in observation space $\mathcal{H}\left(\boldsymbol{x}_{b}\right)$. The operator $\mathcal{H}$ is a generalized interpolator (including model integration to observation time over the assimilation window) from the model grid to the observation location and $\mathbf{H}$ represents its tangent-linear. The fact that the generalised interpolator includes an atmospheric model and interpolation means that it may include a modelling of the observed quantity, such as a radiative transfer code. The $J_{c}(\boldsymbol{\delta} \boldsymbol{x})$ in Eq. (1) is a penalty term controlling gravity waves. In Eqs. (2) and (3), $\mathbf{B}$ and $\mathbf{R}$ respectively represent the background and observation error covariance matrices. In order to assimilate MLS observations, the following changes in the operational version of the 4-D-Var ARPEGE system have been applied. First, the ozone variable is incorporated in the model state vector $\boldsymbol{x}$. Hereafter, the ozone part of $\boldsymbol{x}$ is denoted $\boldsymbol{x}_{\mathrm{O}_{3}}$. The time-space evolution of $\boldsymbol{x}_{\mathrm{O}_{3}}$ is simulated by a passive-tracer advection equation using a semi-lagrangian transport scheme. Second, MLS ozone observations are included in Eq. (3). Third, in contrast to the other meteorological variables for which the background $\boldsymbol{x}_{b}$ of Eq. (2) is provided by the ARPEGE 3-h forecast run, the ozone part of $\boldsymbol{x}_{b}$ (hereafter represented by $\boldsymbol{x}_{b_{\mathrm{O}_{3}}}$ ) is provided by MOCAGE at the beginning time of each 6-h assimilation window. Figure 1 depicts a vertical cross section from $90^{\circ} \mathrm{N}$ to $90^{\circ} \mathrm{S}$ of the normalized differences in the zonal mean ozone fields from MOCAGE (comprehensive chemistry) and ARPEGE (where ozone is only advected) after $6,12,18$ and $24 \mathrm{~h}$ of simulation. It clearly shows that, after $6 \mathrm{~h}$, ozone fields computed by $A R P E G E$ remain very close to the one computed with the dedicated MOCAGE CTM; discrepancies grow after 12$24 \mathrm{~h}$ of simulation, both due to a less appropriate representation of transport and to the lack of chemical source and sink terms in the ARPEGE model. Finally, in the operationally used version of ARPEGE, the part of background-error covariance matrix $\mathbf{B}$ for dynamical meteorological variables is estimated using Analysis Ensemble Method (Houtekamer et al., 1996). In this study, the part of the $\mathbf{B}$ related to $\boldsymbol{x}_{\mathrm{O}_{3}}$ (hereafter represented by $\mathbf{B}_{\mathrm{O}_{3}}$ ) is computed statistically using the NMC method (Parrish and Derber, 1992) with 12/36$\mathrm{h}$ forecast differences. The 12/36-h forecasts are both constructed by integrating the passive-tracer advection equation from an ozone initial condition given by MOCAGE. It must be noticed, here, that the constructed $\mathbf{B}_{\mathrm{O}_{3}}$ matrix corresponds more to the ozone short-term forecasts errors of ARPEGE rather than to the MOCAGE ones, but both errors should be similar for the following reasons: (1) the photochemical lifetime of ozone is relatively long in the UTLS region and (2) MOCAGE uses a dynamical forcing provided by ARPEGE. Further, this way of $\mathbf{B}_{\mathrm{O}_{3}}$ matrix construction has the advantage to provide it on the ARPEGE grid directly. Figure 2a, $\mathrm{b}$, and $\mathrm{c}$ respectively depict pressure, ozone average vertical correlations and ozone horizontal correlation scale as a function of model levels in the UTLS. Figure $2 b$ shows that the vertical correlation length of $\boldsymbol{x}_{b_{\mathrm{O}_{3}}}$ errors is small in the stratosphere and increases towards the tropopause. Furthermore, ozone is assimilated in a univariate manner: no correlation is specified between ozone and wind (relative vorticity) in the formulation of the $\mathbf{B}$ matrix. The univariate ozone background errors were chosen because they minimize the feedback effects of ozone on other meteorological variables (Dethof and Holm, 2004). Therefore, ozone observations affect the analysis of the meteorological fields only through the coupling of trace gas concentration and air transport. No ozone/radiation interaction is included: the ozone climatology of Fortuin and Langematz (1995) is used in the radiation scheme. Observation operator calculations within satellite radiances assimilation (e.g., ozone-sensitive channel 9 of 

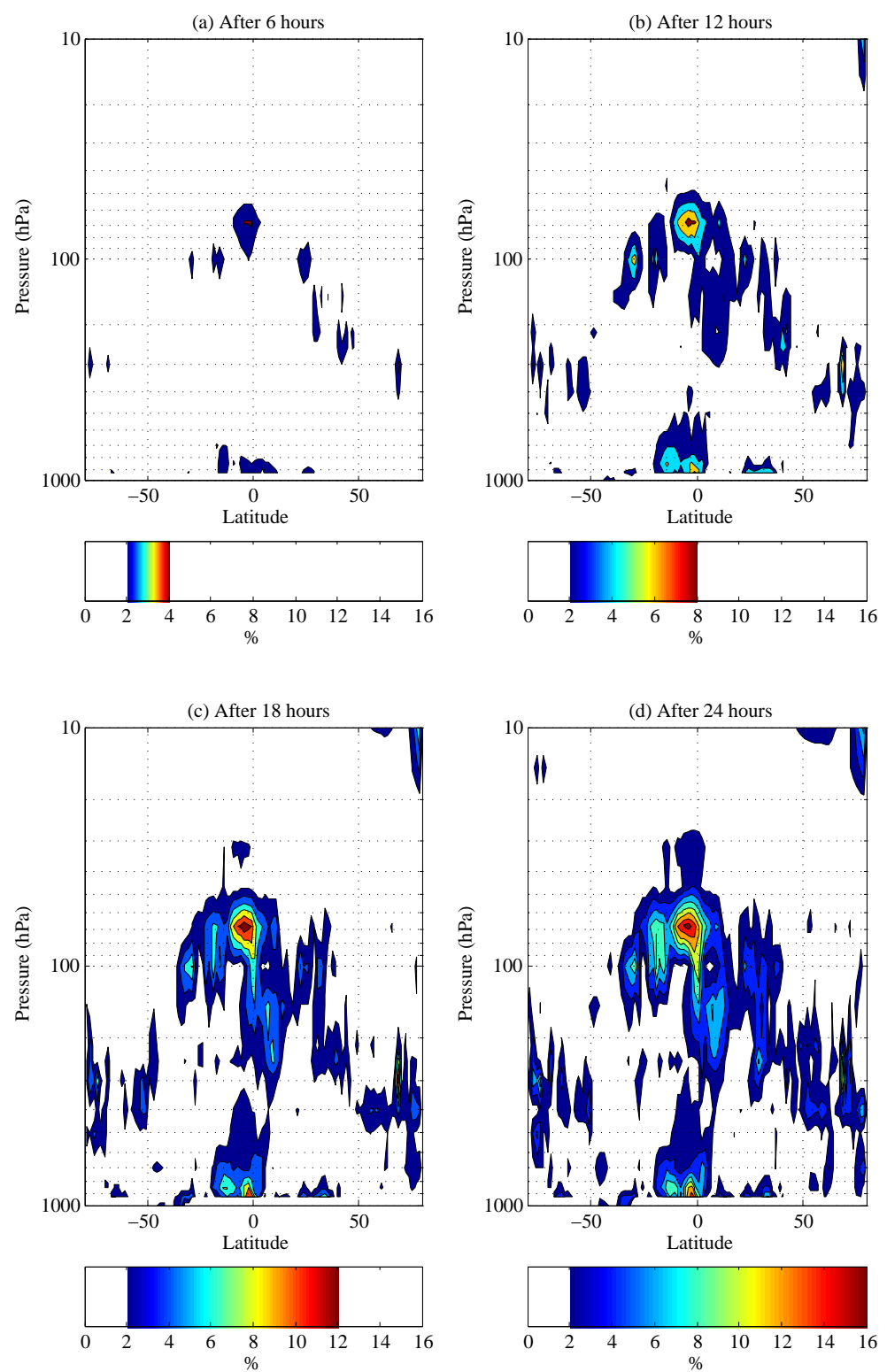

Fig. 1. MOCAGE and ARPEGE ozone zonal mean difference percentage, $100 \times \frac{|A R P E G E-M O C A G E|}{M O C A G E}$, after 6 (a), 12 (b), 18 (c) and $24 \mathrm{~h}$ (d) of simulation.

HIRS and channel 18 of AMSU-B) also use ozone climatology instead of the new introduced model ozone.

The use of MOCAGE for the background initialization at the beginning of each assimilation cycle is a key component of this study. This initialization replaces the ARPEGE transported ozone field by more realistic values given the fact that the MOCAGE CTM takes into account many processes, which simulate more accurately the ozone evolution in comparison to the only advection process of the ARPEGE model. Moreover, the ARPEGE ozone transport scheme is not very robust, even in places where the photochemical lifetime is very important as the UTLS, in comparison to the MOCAGE transport scheme. Therefore, the ozone field of ARPEGE is updated after 6 hours of simulation in order to prevent its divergence.

\subsection{Experiment setup}

In order to investigate the impact of the assimilation of MLS ozone profiles on ARPEGE wind fields, two assimilation experiments have been run at a regular low resolution of T107 truncation on 41 levels from the ground up to $1 \mathrm{hPa}$. The operational version was at a resolution of T358 (stretched grid) on 41 levels in 2006; the current (2008) operational version 

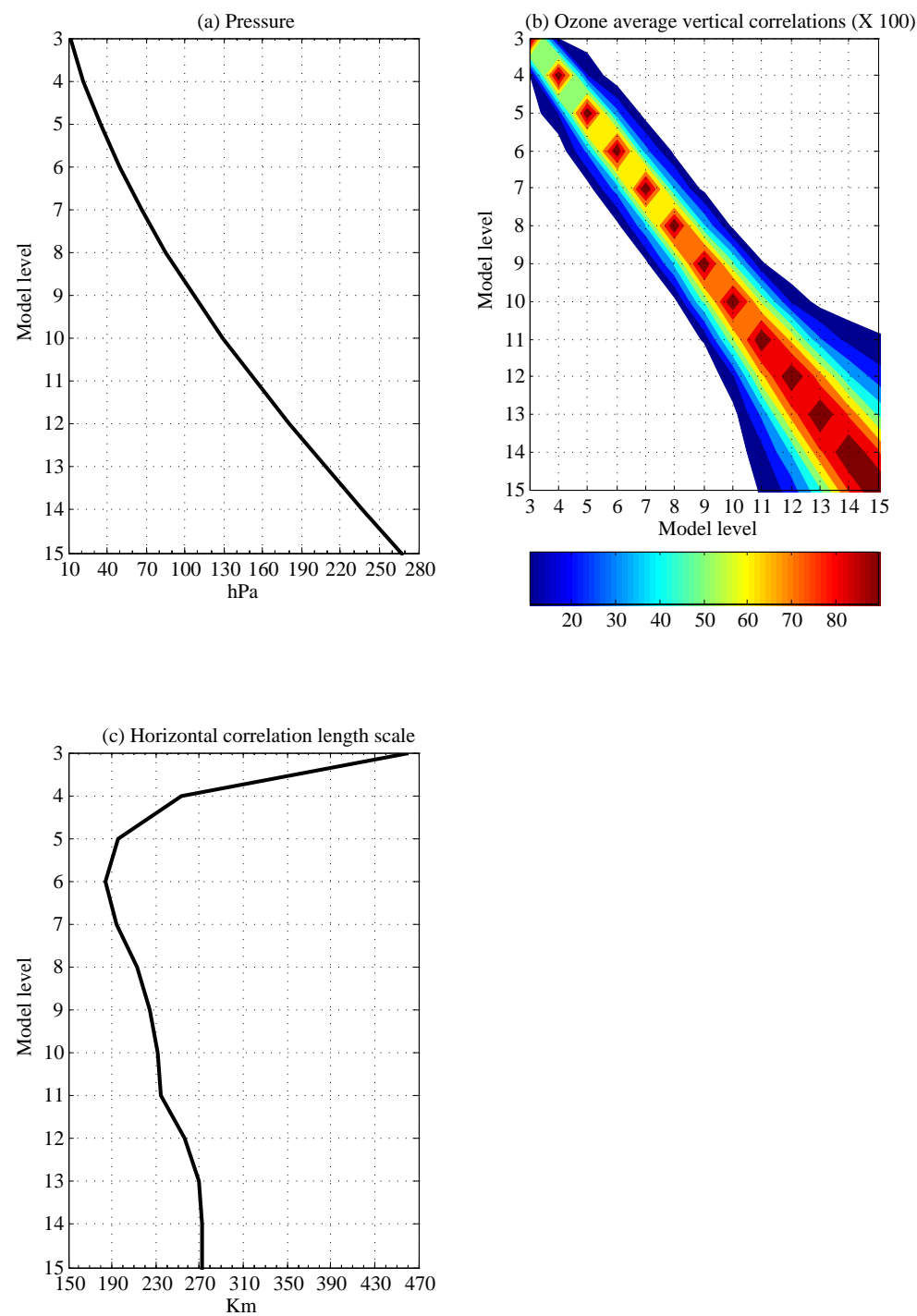

Fig. 2. (a) Pressure as a function of model levels in the UTLS, (b) Ozone average vertical correlations, and (c) Ozone horizontal correlation scale as a function of model levels in the UTLS.

is at a resolution of T538 on 60 levels. In the first experiment (denoted CTL), MLS data are not assimilated. In the second experiment (denoted MLS), MLS ozone profiles, between 215.4 and $1 \mathrm{hPa}$ in the extratropics and between 147 and $1 \mathrm{hPa}$ in the latitudes range $\left(30^{\circ} \mathrm{S}-30^{\circ} \mathrm{N}\right)$, are assimilated. The MLS and CTL experiments are run over a period of 3 months from 23 January to 22 April 2006. The ozone field is produced by MOCAGE and is only transported over the $6 \mathrm{~h}$ assimilation window via ARPEGE. The spinup time was taken into account in the MOCAGE simulation, which was performed 2 months before the beginning of the assimilation experiment starting on 23 January 2006. Other assimilated observations in the CTL and MLS experiments are based on the operational data including surface observations, radiosondes, aircraft reports, and wind profil- ers, as well as satellite observations such as winds from the geostationary satellites, MODIS winds, QuikSCAT winds, and radiance data from both HIRS and AMSU (Unit-A and Unit-B) sounders aboard the National Oceanic and Atmospheric Administration polar-orbiting satellites (NOAA-15, NOAA-16 and NOAA-17). 4-D-Var assimilates observations within $+/-3 \mathrm{~h}$ of the analysis time (00:00, 06:00, 12:00 and 18:00 UTC). This is in line with the current operational setup in $A R P E G E$, as this study aims at being in a fully realistic NWP context. The flow of 4-D-Var procedure for the case of 12:00 UTC analysis time is given in Fig. 3. 

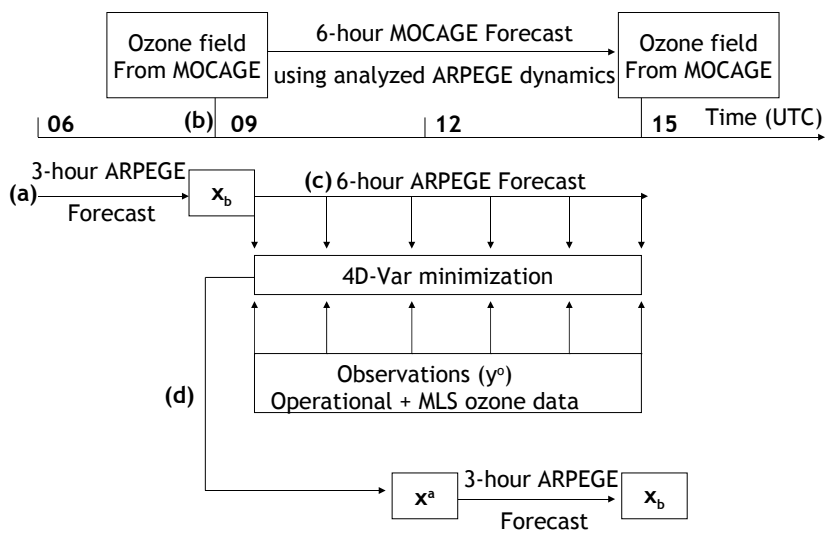

Fig. 3. Flow of 4-D-Var procedure for the case of 12:00 UTC analysis time. (a) 3-h forecast from previous ARPEGE analysis is used as background $\boldsymbol{x}^{b}$, (b) The ozone background field is provided by MOCAGE, (c) 6-h forecast from $\boldsymbol{x}^{b}$ to perform the innovation vector, $\boldsymbol{d}=\boldsymbol{y}^{\circ}-\mathcal{H}\left(\boldsymbol{x}^{\boldsymbol{b}}\right)$, over a 6-h assimilation window (09:00 UTC15:00 UTC), and (d) After the 4-D-Var minimization, the increment analysis is added to the first guess field (valid at 12:00 UTC) to obtain the analysis $\boldsymbol{x}^{a}$ at 12:00 UTC.

\section{Ozone data dynamical impact study}

\subsection{OMA and OMF ozone statistics}

Figure 4 displays $100 \times \frac{\mathrm{OMA}}{\boldsymbol{y}^{\boldsymbol{0}}}$ (solid line with squares) and $100 \times \frac{\mathrm{OMF}}{y^{\circ}}$ (dashed line with circles) both averaged in time from 23 January to 21 February 2006 (00:00 and 12:00 UTC analysis times) and over the following latitude bands (a) $30^{\circ} \mathrm{N}-90^{\circ} \mathrm{N}$, (b) $30^{\circ} \mathrm{N}-30^{\circ} \mathrm{S}$, and (c) $30^{\circ} \mathrm{S}-90^{\circ} \mathrm{S}$. Here, OMA and OMF respectively refer to Observation minus Analysis and Observation minus First-guess for ozone. This shows that when MLS data are assimilated, the departures are reduced and the analysis agrees better with the MLS data in comparison to the background. For instance, the assimilation of MLS profiles corrects the background overestimation of ozone in the Northern Hemisphere, by driving the analyses to a value slightly close to MLS observations owing to the negative correction induced by the analysis increment. This overestimation feature of the background has been already diagnosed by El Amraoui et al. (2008a) during winter months inside the vortex. The reverse process occurs in the tropics and the Southern Hemisphere at pressure levels greater than $46.4 \mathrm{hPa}$, where there is a substantial correction of the model underestimation of ozone.

It must be noticed, here, that OMA and OMF ozone statistics only shows that the system is behaving properly. Therefore, further information on system performance can be obtained by comparison against independent data.

\subsection{OMF wind statistics}

The OMF residuals produced by a data assimilation system provide a convenient metric of evaluating global analyses. Here, OMF statistics from ARPEGE are used to examine how wind assimilation output and their associated OMF bias and standard deviation are affected by the additional assimilation of MLS ozone data. Specifically, ARPEGE wind fields (zonal and meridional components) from the first-guess, 24$\mathrm{h}$ and 48-h forecasts are compared against radiosondes for experiments with and without MLS ozone data. OMF are averaged in time from 23 January to 22 April 2006 (for 00:00 and 12:00 UTC) and over the globe. The number of observations per pressure level, used in the OMF statistics, is given in Table 1. Figure 5 depicts vertical profiles of OMF bias for the CTL (solid line) versus the MLS experiment (dashed line) for both zonal (left hand-side panels) and meridional (right hand-side panels) wind components. The top, middle and bottom panels correspond to the first guess, 24-h and 48-h forecasts, respectively. In comparison to the CTL, the MLS experiment has smaller biases in the lower stratosphere for both zonal and meridional winds. The middle and bottom panels of Fig. 5 confirm that information added in the MLS experiment is successfully retained in the 24/48-h forecasts in the lower stratosphere. OMF standard deviations, not shown here, are very close for both experiments. Overall, the addition of MLS ozone data improves the agreement between the wind fields and the verifying radiosondes data over the globe. The observation minus first guess biases (top panels of Fig. 5) show that the wind response signal due to the MLS data assimilation is nearly vertically uniform between 20 and $100 \mathrm{hPa}$ for the zonal component. It has, however, a pronounced positive peak between 30 and $50 \mathrm{hPa}$ for the meridional wind component. This response signal difference between the two components of the wind has also been pointed out by Riishøjgaard (1996). In fact, the direction of the flow with respect to the gradient of the tracer concentration is a key parameter that governs the wind response to the tracer data assimilation. Indeed, when the flow is aligned with the gradient of the tracer concentration, the tracer assimilation affects considerably the wind during the adjoint calculation (this can be easily inferred from the simplified Euler-Lagrange equations used by Holm et al. 1999). In the top right-hand side panel of Fig. 5, the peak in the bias reduction of the wind meridional component corresponds to the altitudes where the meridional component of ozone gradient is large; this is typically true for the middle and high latitudes. To summarize, the MLS ozone data provide a beneficial signal in the ARPEGE wind fields. Even though the ozone data dynamical impact is not very large, it is not neutral and mostly positive over a meteorological data sparse region (e.g., the lower stratosphere). It must be noticed that the dynamical impact of the MLS data depends very much on how the information contained in the data is extracted and incorporated into the initial condition. Yet, a good MLS 

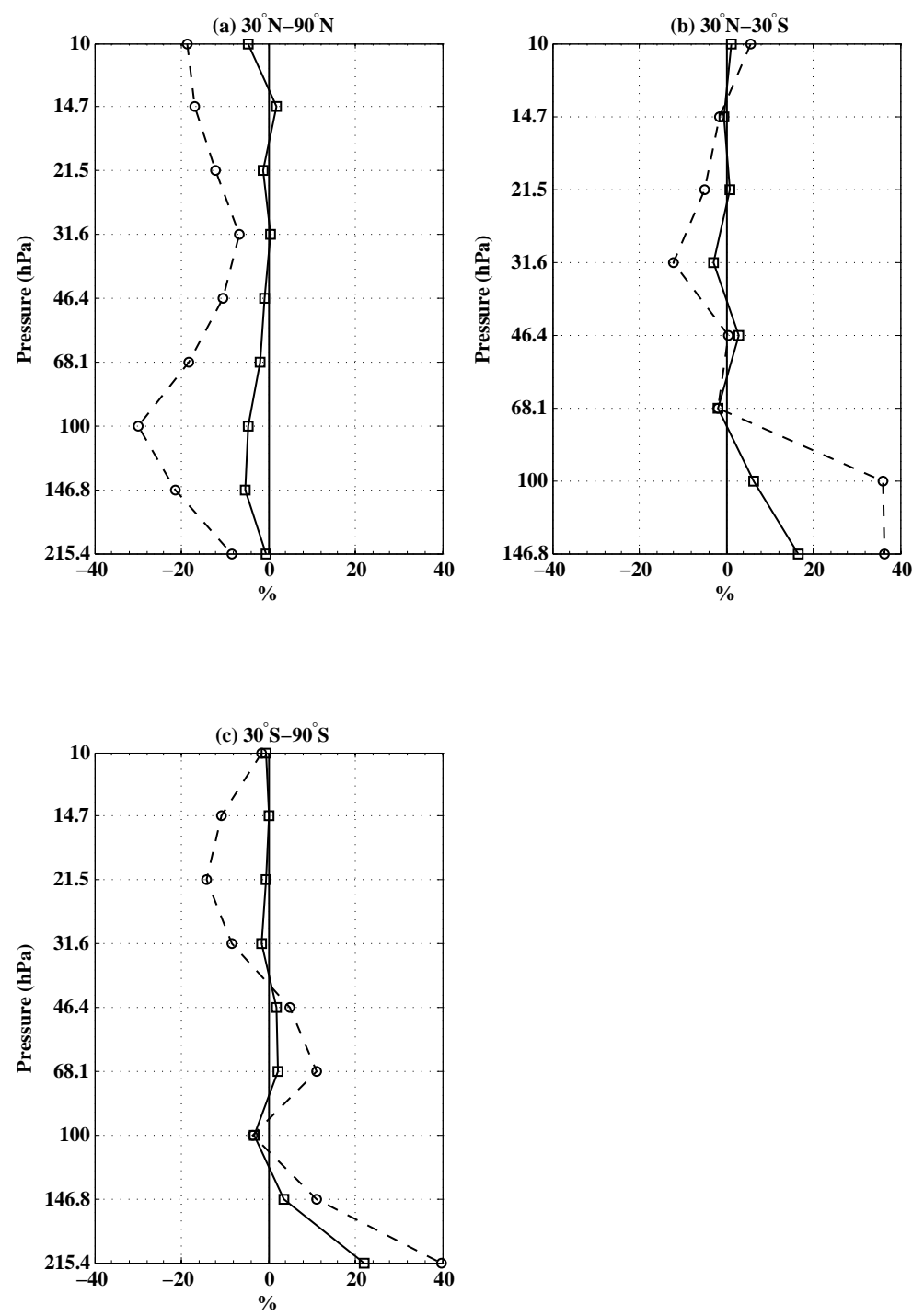

Fig. 4. $100 \times \frac{O M A}{y^{\circ}}$ (solid line with squares) and $100 \times \frac{O M F}{y^{0}}$ (dashed line with circles) for ozone, both averaged in time from 23 January to 21 February 2006 (00:00 and 12:00 UTC analysis times) and over the following latitude bands (a) $30^{\circ} \mathrm{N}-90^{\circ} \mathrm{N}$, (b) $30^{\circ} \mathrm{N}-30^{\circ} \mathrm{S}$, and (c) $30^{\circ} \mathrm{S}-90^{\circ} \mathrm{S}$.

dataset, which is unbiased with respect to the background, could probably improve the wind analysis even more. Note that, in this work, no bias correction has been applied in the first approach.

\subsection{Degrees of Freedom for Signal}

A traditional way of estimating data impact in a assimilation system is to perform Observing System Experiments (OSEs). It consists of removing one particular dataset over a long assimilation period. One then evaluates the forecast scores, compared to a reference assimilation using the complete set of observations (Bouttier and Kelly, 2001). This procedure provides the impact of observations on the forecasts and not on the analyses themselves (Desroziers et al., 2005). In the perspective of diagnosing the direct impact of observations on the analyses, other diagnostics such as Degree of Freedom for Signal and variance reduction were developed. This study is based on these two diagnostics. The Degrees of Freedom for Signal (DFS) provide a measure of the gain in information brought by the observations (Rodgers, 2000; Fisher, 2003). In a linear framework, DFS is algebraically defined by the trace of the HK matrix

$\mathrm{DFS}=\operatorname{Tr}(\mathbf{H K})$

where $\mathbf{K}$ refers to the Kalman gain matrix, which only depends on the specified statistics of the assimilating system

$\mathbf{K}=\mathbf{B H}^{T}\left(\mathbf{H B H}^{T}+\mathbf{R}\right)^{-1}$ 

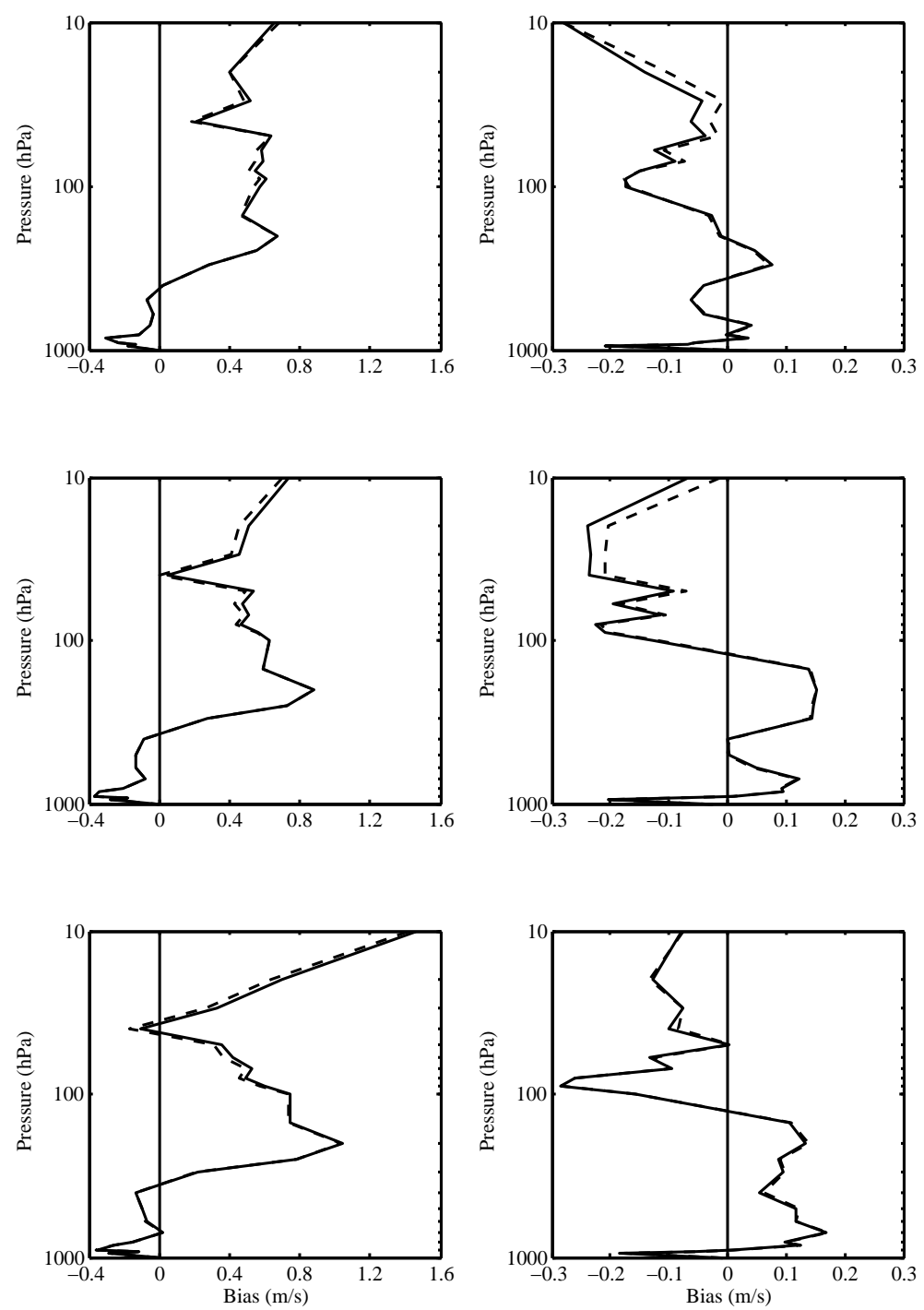

Fig. 5. Comparison of ARPEGE winds against radiosondes. Observation minus forecast residuals (OMF) are globally and time averaged from 23 January to 22 April 2006 for the CTL experiment (solid line) and the MLS experiment (dashed line) for both zonal (left hand-side panels) and meridional (right hand-side panels) wind components. The top, middle and bottom panels correspond to the first guess, 24-h and 48-h forecasts, respectively.

Like in Chapnik et al. (2006), the DFS is approximated here by using the method of Desroziers and Ivanov (2001). Indeed, one normal ozone analysis $x^{a}$ and a perturbed one $\boldsymbol{x}^{a *}$, performed with perturbed observations $\boldsymbol{y}^{\boldsymbol{\sigma} *}$ based on the method of Desroziers et al. (2005), are used to estimate the partial Degrees of Freedom for Signal associated with a particular subset of observations (called $\mathrm{DFS}_{i}$ ) through the following expression:

$\mathrm{DFS}_{i}=\boldsymbol{\delta} \boldsymbol{y}_{\boldsymbol{i}}^{\boldsymbol{o} T} \mathbf{R}_{i}^{-1} \Pi_{i} \mathbf{H} \boldsymbol{\delta} \boldsymbol{x}^{\boldsymbol{a}}\left(\boldsymbol{\delta} \boldsymbol{y}^{\boldsymbol{o}}\right)$

where the subscript $i$ refers to a specific subset and $\mathbf{R}_{i}$ presents its observation error covariance matrix. $\Pi_{\mathbf{i}}$ is the projection operator that allows us to pass from the complete dataset used in the assimilation to the subset $i . \delta y_{i}^{o}=\Pi_{i} \delta y^{o}$ is the projection of the vector of perturbations $\delta y^{o}$ onto the subset $i$,

$\delta y^{o}=y^{o *}-y^{o}$

and $\delta x^{a}\left(\delta y^{o}\right)$ is the perturbation on the analysis produced by a perturbation on the complete assimilated dataset:

$\delta x^{a}\left(\delta y^{o}\right)=x^{a *}-x^{a}$

The partial Degrees of Freedom for Signal associated with a particular subset of observations can be determined if the associated error characteristics of these observations are not 

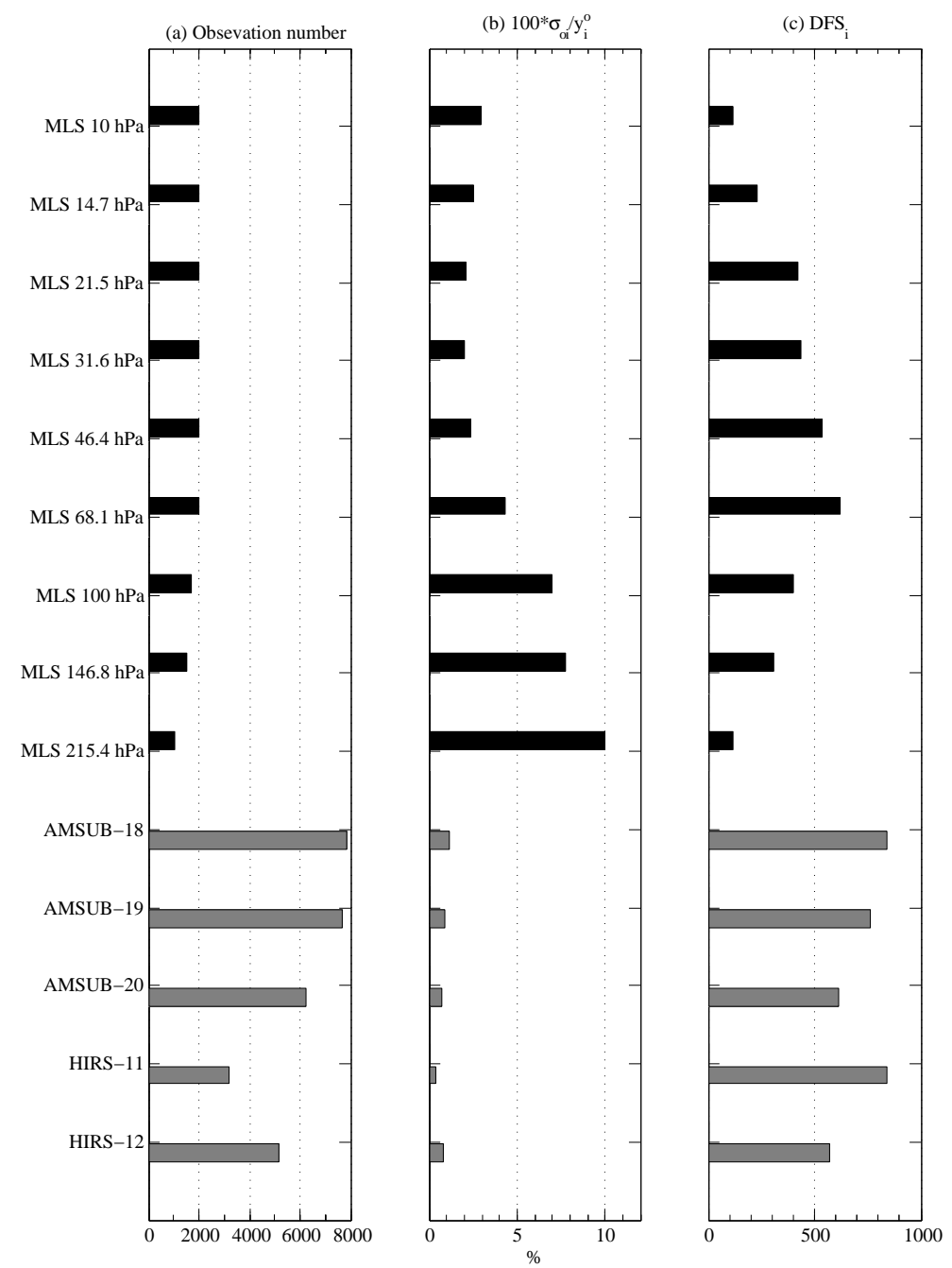

Fig. 6. (a) Observation number averaged in time from 23 January to 21 February 2006 (00:00 and 12:00 UTC analysis times) and over the globe for the following specific subsets: MLS ozone data on specific pressure levels and humidity-sensitive channel radiances from the HIRS sounder on NOAA-16 (channels 11 and 12) and the AMSU-B sounders on NOAA-16 and NOAA-17 (channels 18, 19 and 20), (b) 100× $\frac{\boldsymbol{\sigma}_{\boldsymbol{o}} i}{\boldsymbol{y}_{i}}$ averaged over the globe and over the same period and for the same data as before, $(\mathbf{c}) \mathrm{DFS}_{i}$ averaged over the same period and for the same data as before.

correlated to the rest of the observation errors in the specified $\mathbf{R}$ matrix. In fact, if it is assumed that the complete set of observations can be split between observation subsets with independent errors, then matrix $\mathbf{R}$ is block-diagonal. The complete assimilated dataset over a 6 -h assimilation window is perturbed one-time and the Eq. (6) is evaluated for each assimilation cycle for a one-month period.

Figure $6 \mathrm{a}, \mathrm{b}$ and $\mathrm{c}$ respectively show the observation number, $100 \times \frac{\sigma_{o i}}{\boldsymbol{y}_{i}^{o}}$ and $\mathrm{DFS}_{i}$, all averaged in time from 23 January to 21 February 2006 (00:00 and 12:00 UTC analysis times) and over the globe for the following specific subsets: MLS ozone data on specific pressure levels and humidity-sensitive channel radiances from the HIRS sounder on NOAA-16 (channels 11 and 12) and the AMSU-B sounders on NOAA-
16 and NOAA-17 (channels 18, 19 and 20). $\sigma_{o i}$ refers to the observation-error of the subset $i$. One can see that the MLS data covering the $68.1-31.6 \mathrm{hPa}$ vertical pressure range are the most informative and their information content is nearly of the same order as humidity-sensitive channel radiances. The fact that the first pressure 100-215.4 hPa range does not provide significantly more information in comparison to the pressure $68.1-31.6 \mathrm{hPa}$ range, is probably due to a combination of factors. First, the variances of observation error for the first range are significantly greater than those of the second one. Second, the assumed horizontal correlation of background errors introduces a degree of redundancy into the information provided by the observation within the scale length of the correlation. This latter is smaller for the second pressure range in comparison to the first one (see Fig. 2c). 

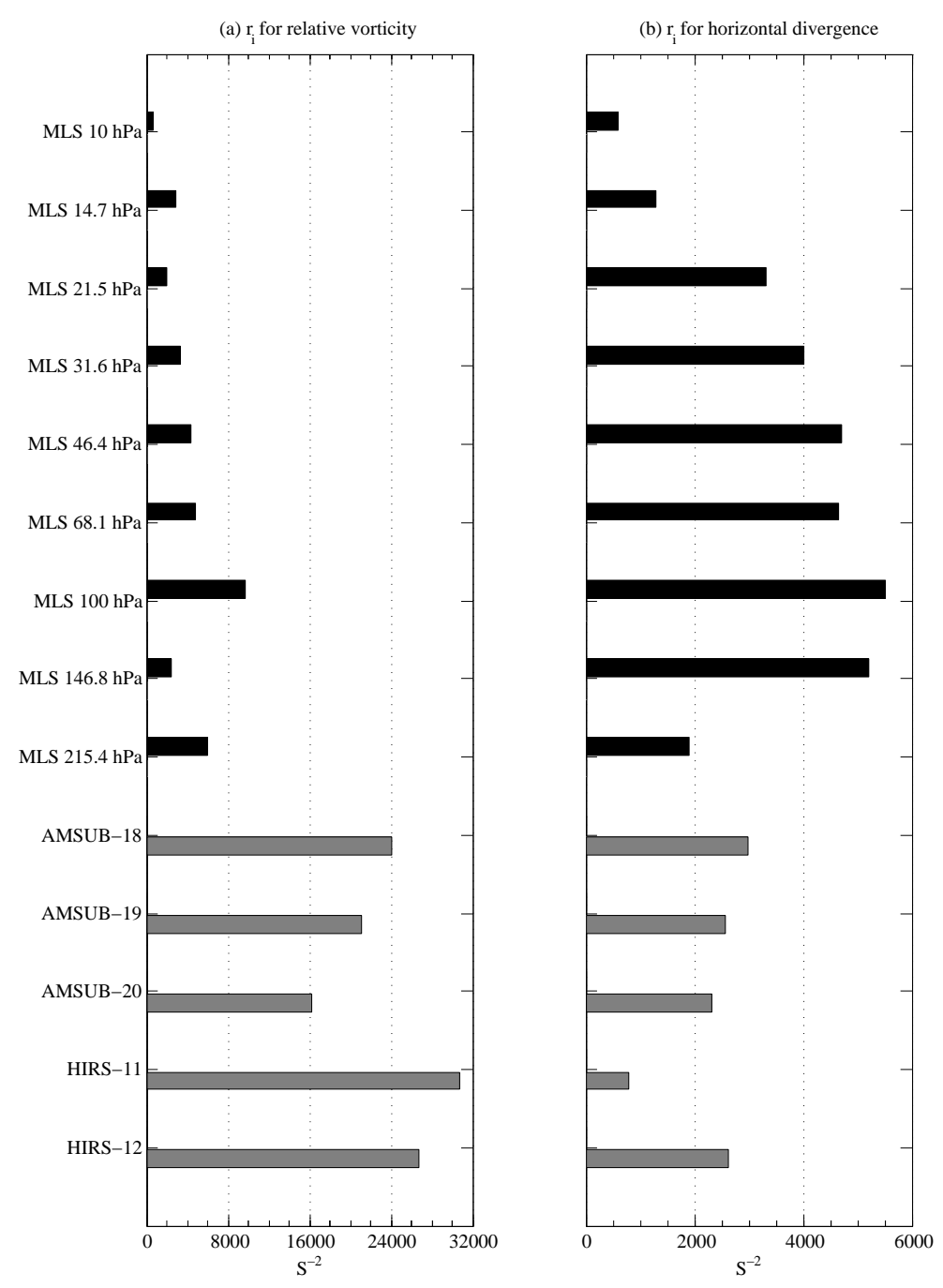

Fig. 7. Error variance reduction $\left(r_{i}\right)$ mean for relative vorticity (a) and horizontal divergence (b) brought by the following specific subsets: MLS ozone data on specific pressure levels and humidity-sensitive channel radiances from the HIRS sounder on NOAA-16 (channels 11 and 12) and the AMSU-B sounders on NOAA-16 and NOAA-17 (channels 18,19 and 20). The mean is obtained by averaging the daily $r_{i}(00: 00$ and 12:00 UTC analysis times) of a one-month period from 23 January 2006 to 21 February 2006.

\subsection{Error variance reduction diagnostics}

The error variance reduction method introduced by Desroziers et al. (2005) diagnoses the direct impact of a specific observation subset on a specific analysis field. It provides, hence, useful information on the use of observations in an operational analysis. It is used here in order to objectively diagnose the impact of ozone data on the wind analysis in terms of horizontal divergence and relative vorticity, in comparison to humidity-sensitive channel radiances from both HIRS and AMSU-B sounders. The error variance reduction, for horizontal divergence or relative vorticity, is estimated by using the following expression:

$r_{i}=\delta y_{i}^{o T} \mathbf{R}_{\mathbf{i}}^{-1} \Pi_{\mathbf{i}} \mathbf{H B L}^{\mathrm{T}} \mathbf{L} \delta \mathbf{x}^{a}\left(\delta \mathbf{y}^{o}\right)$ where $\mathbf{L}$ is a mapping, which corresponds here to a projection operator onto the two selected model variables that are directly linked to the wind field: horizontal divergence and relative vorticity. DFS $i$ can be derived from the $r_{i}$ expression by considering the special case of $\mathbf{L}=\mathbf{B}^{-1 / 2}$.

Figure 7 presents $r_{i}$ for relative vorticity (a) and horizontal divergence (b) averaged over the same period and for the same data as those used for the $\mathrm{DFS}_{i}$ diagnostics. It clearly shows that the contribution of MLS ozone dataset to the reduction in error between the background error and the analysis error of wind fields is larger for horizontal divergence field in comparison to HIRS and AMSU-B channel contributions. The vertical distribution of error variance reductions brought by ozone data for both horizontal diver- 
Table 1. Number of radiosonde observations (N. Obs) per pressure level in hPa, used in OMF wind statistics.

\begin{tabular}{cccccccc}
\hline Pressure (hPa) & N. Obs. & Pressure (hPa) & N. Obs & Pressure (hPa) & N. Obs & Pressure (hPa) & N. Obs \\
\hline 10 & 137905 & 70 & 150144 & 250 & 196573 & 600 & 108615 \\
20 & 165619 & 100 & 206210 & 300 & 199299 & 700 & 188118 \\
30 & 170677 & 150 & 228913 & 400 & 190044 & 850 & 140236 \\
50 & 159185 & 200 & 214988 & 500 & 186961 & 925 & 103808 \\
\hline
\end{tabular}

gence and relative vorticity is not uniform as a function of pressure. The lower pressure levels of MLS in the UTLS (100-215.4 hPa) has the most important influence on relative vorticity. This was expected as there is a strong correlation between ozone and potential vorticity in the vicinity of the tropopause level. The difference between $\mathrm{DFS}_{i}$ and $r_{i}$ at these levels could be the fact that the assumed horizontal correlation of background errors introduces a degree of redundancy into the information provided by the observation within the scale length of the correlation leading to a smaller $\mathrm{DFS}_{i}$ in comparison to $r_{i}$. Besides, the relative vorticity and horizontal divergence fields are not influenced by ozone in a similar way. This is likely a manifestation of the multivariate analysis structures implied by the balance operator (based on the geostrophic linear balance between mass and wind). Further, the large error variance reductions brought by humidity radiances on relative vorticity compared to those on horizontal divergence, can be explained by the fact that these radiances (e.g., HIRS channels) are rather sensitive to temperature (but to a lesser extent when compared to humidity). This gives them the possibility to affect the relative vorticity not only via the 4-D-Var wind-humidity coupling, but also implicitly through the balance operator owing to the temperature-relative vorticity correlations. Note that humidity-sensitive radiances can also influence the analysis of the temperature field and thereby its background-error variance reduction, through the model physics given the fact that temperature analysis response is dependent on the "drying" or "wetting" analysis effect of these radiances. Model dynamics are able to efficiently extract information on an unobserved component of the flow (the wind) from information on both humidity and ozone data. Intrinsically linked to the four-dimensional nature of the assimilation, the wind-ozone and wind-humidity couplings generate wind increments both from ozone and humidity-sensitive measurements leading to the reduction of the wind background error variance. As it has been elegantly introduced by Andersson et al. (1994), the process could be described as retrieval/assimilation of "water-vapor winds" from humidity-sensitive radiances and of "ozone winds" from MLS observations.

\section{Conclusions}

In this work, MLS ozone profiles have been assimilated in the ARPEGE 4-D-Var together with operational observations. This was carried out to determine to what extent the wind-ozone coupling, within the forecast model and its adjoint, could provide wind increments in response to remotely-sensed MLS ozone information. In the designed MLS assimilation experiment the ozone is re-initialized from the MOCAGE CTM every $6 \mathrm{~h}$, however, the meteorological fields continue their temporal evolution through the assimilation cycles.

A data impact study with 4-D-Var analysis was conducted from 23 January to 22 April 2006. The statistics on observation minus forecast produced by ARPEGE allowed a description of how the ozone observations affect wind fields. Indeed, it was found that the major impact of ozone on wind fields, diagnosed within the MLS data assimilation experiment, consists of a slight improvement in the wind fields in the lower stratosphere where meteorological data are sparse. In addition, the forecasts issued after assimilation of MLS ozone data are found to be closer to the wind observations than the forecasts issued without MLS. Further, the Degrees of Freedom for Signal diagnostics showed that the MLS data covering the $68.1-31.6 \mathrm{hPa}$ vertical pressure range are the most informative and their information content is nearly of the same order as humidity-sensitive radiances. Furthermore, the error variance reduction diagnostics showed that MLS ozone observations positively contribute to the reduction of the global initial background error variance of the wind fields. Moreover, they bring additional information and in terms of horizontal divergence, this contribution is larger than that given by HIRS and AMSU-B. 
The main conclusion is that it is possible to improve the wind simulation of ARPEGE by adding MLS ozone data to the assimilation system. The improvement of lower stratospheric wind forecasts inferred from MLS data demonstrated the potential benefit for including ozone assimilation in an operational framework.

Now as the dynamical impact of the real ozone observations is found to be positive, the next step of this work will concentrate more on the optimal estimation of the background error covariance matrix, which should be based on the MOCAGE forecast differences and not on the ARPEGE ones. Besides, given the fact that both HIRS 9 and AMSUB 18 channels have ozone Jacobians that peak in the UTLS, and since assimilating EOS MLS data seems to give a more accurate ozone analysis in this region, the use of the assimilated ozone in the HIRS and AMSU-B observation operator calculations may improve radiance assimilation, compared to the case where ozone climatology is used.

In ongoing work, the impact of dynamical forcing resulted from ARPEGE (from the MLS experiment) on the MOCAGE CTM, is under examination. In fact, the new meteorological fields produced by the MLS experiment are used as new dynamical forcing for MOCAGE. The impact of this new forcing on MOCAGE in terms of ozone evolution will be assessed in comparison to a control run of MOCAGE using the standard dynamical forcing derived from the ARPEGE control experiment without MLS assimilation. As the MLS data are not available in near-real time, their assimilation could not be implemented in an operational weather forecasting. However, one could envision the assessment, as done in this work, of the derived benefit from assimilating ozone data (IASI and GOME-2 instruments) of Metop satellite measurements launched on 19 October 2006, and which are available in near-real time to operational centres.

Acknowledgements. The authors would like to thank Jean Pailleux from Météo-France for his useful suggestions. This research is supported by Météo-France and the Centre National d'Etudes Spatiales (CNES). This work was also supported in the context of the EU-funded Framework V project ASSET (contract EVK2CT-2002-00137). MLS data were downloaded from the NASA Goddard Space Flight Center.

Edited by: W. Lahoz

\section{References}

Andersson, E., Pailleux, J., Thépaut, J.-N., Eyre, J. R., McNally, A. P., Kelly, G. A., and Courtier, P.: Use of cloud-cleared radiances in three/four-dimensional variational data assimilation, Q. J. Roy. Meteor. Soc., 120, 627-653, 1994.

Bouttier, F. and Kelly, G.: Observing-system experiments in the ECMWF 4-D-Var data assimilation system, Q. J. Roy. Meteor. Soc., 127, 1469-1488, 2001.

Cariolle, D. and Morcrette, J.-J.: A linearized approach to the radiative budget of the stratosphere influence of the ozone distribution,
Geophys. Res. Lett., 33, L05806, doi:10.1029/2005GL025597, 2006.

Chapnik, B., Desroziers, G., Rabier, F., and Talagrand, O.: Diagnosis and tuning of observational error statistics in a quasioperational data assimilation setting, Q. J. Roy. Meteor. Soc., 132, 543-565, 2006.

Courtier, P., C. Freydier, Geleyn, J.-F., Rabier, F., and Rochas, M.: The ARPEGE project at Météo-France, in Workshop on numerical methods in atmospheric models, 2, 193-231, 1991.

Daley, R.: Estimating the Wind Field from Chemical Constituent Observations: Experiments with a One-Dimensional Extended Kalman Filter, Mon. Weather. Rev., 123, 181-198, 1995.

Danielsen, E. F.: Stratospheric-tropospheric exchange based on radioactivity, ozone and potential vorticity, J. Atmos. Sci., 25, 502518, 1968.

Davis, C., Low-Nam, S., Shapiro, M. A., Zou, X., and Krueger, A. J.: Direct retrieval of wind from Total Ozone Mapping Spectrometer (TOMS) data: Examples from FASTEX, Q. J. Roy. Meteor. Soc., 125, 3375-3391, 1999.

Derber, J. C. and Wu, W.-S.: The use of TOVS cloud-cleared radiances in the NCEP SSI analysis system, Mon. Weather Rev., 126, 2287-2302, 1998.

Desroziers, G. and Ivanov, S.: Diagnosis and adaptivee tuning of information error parameters in a variational assimilation, Q. J. Roy. Meteor. Soc., 127, 1433-1452, 2001.

Desroziers, G., Brousseau, P., and Chapnik, B.: Use of randomization to diagnose the impact of observations on analyses and forecasts, Q. J. Roy. Meteor. Soc., 131, 2821-2837, 2005.

Dethof, A. and Holm, E. V.: Ozone assimilation in the ERA-40 reanalysis project, Q. J. Roy. Meteor. Soc., 130, 2851-2872, 2004.

Dufour, A., Amodei, M., Ancellet, G., and Peuch, V.-H. : Observed and modelled "chemical weather" during ESCOMPTE, Atmos. Res., 74(1-4), 161-189, 2004.

El Amraoui, L., Peuch, V.-H., Ricaud, P., Massart, S., Semane, N., Teyssèdre, H., Cariolle, D., and Karcher, F.: Ozone loss in the 2002-2003 Arctic vortex deduced from the assimilation of Odin/SMR $\mathrm{O}_{3}$ and $\mathrm{N}_{2} \mathrm{O}$ measurements: $\mathrm{N}_{2} \mathrm{O}$ as a dynamical tracer, Q. J. Roy. Meteor. Soc., 134, 217-228, 2008a.

El Amraoui, L., Semane, N., Peuch, V.-H., and Santee, M. L.: Investigation of dynamical processes in the polar stratospheric vortex during the unusually cold winter 2004/2005, Geophys. Res. Lett., 35, L03803, doi:10.1029/2007GL031251, 2008 b.

Eskes, H., Segers, A., and van Velthoven, P.: Ozone forecasts of the stratospheric polar vortex-splitting event in September 2002, J. Atmos. Sci., 62, 812-821, 2005.

Feng, L., Brugge, R., Holm, E. V., Harwood, R. S., O’Neill, A., Filipiak, M. J., Froidevaux, L., and Livesey, N.: Four-dimensional variational assimilation of ozone profiles from the Microwave Limb Sounder on the Aura satellite, J. Geophys. Res., 113, D15S07, doi:10.1029/2007JD009121, 2008.

Fisher, M.: Estimation of entropy reduction and degrees of freedom for signal for large variational analysis systems, Technical Memo., 397, ECMWF, Reading, UK, 2003.

Fortuin, J. and Langematz, U.: An update on the global ozone climatology and on concurrent ozone and temperature trends, In SPIE Proceedings Series: Atmospheric Sensing and Modeling, 2311, 207-216, 1995.

Froidevaux, L., Livesey, N. J., Read, W. G., et al.: Early validation analyses of atmospheric profiles from EOS MLS on the Aura 
satellite, IEEE T. Geosci. Remote Sens., 44, 1106-1121, 2006.

Geer, A. J., Lahoz, W. A., Bekki, S., Bormann, N., Errera, Q., Eskes, H. J., Fonteyn, D., Jackson, D. R., Juckes, M. N., Massart, S., Peuch, V.-H., Rharmili, S., and Segers, A.: The ASSET intercomparison of ozone analyses: method and first results, Atmos. Chem. Phys., 6, 5445-5474, 2006,

http://www.atmos-chem-phys.net/6/5445/2006/.

Hollingsworth, A., Engelen, R. J., Textor, C., Benedetti, A., Boucher, O., Chevallier, F., Dethof, A., Elbern, H., Eskes, H., Flemming, J., Granier, C., Kaiser, J. W., Morcrette, J.-J., Rayner, P., Peuch, V.-H., Rouil, L., Schultz, M. G., Simmons, A. J., and the GEMS Consortium: Towards a monitoring and forecasting system for atmospheric composition: The GEMS Project, B. Am. Meteor. Soc., 89(8), 1147-1164, 2008.

Holm, E. V., Untch, A., Simmons, A., Saunders, R., Bouttier, F., and Andersson, E.: Multivariate ozone assimilation in fourdimensional data assimilation, In Proceedings of the SODA Workshop on Chemical Data Assimilation, 89-94, KNMI, De Bilt, The Netherlands, 9-10 December 1998, 1999.

Houtekamer, P. L., Lefaivre, L., Derome, J., Ritchie, H., and Mitchell, H. L.: A system simulation approach to ensemble prediction, Mon. Weather Rev., 124, 1225-1242, 1996.

Ide, K., Courtier, P., Ghil, M., and Lorenc, A. C.: Unified notation for data assimilation: operational, sequential and variational, J. Met. Soc. Japan, 75, 181-189, 1997.

Jackson, D. R.: Assimilation of EOS MLS ozone observations in the Met Office data-assimilation system, Q. J. Roy. Meteorol. Soc., 133, 1771-1788, 2007.

John, V. O. and Buehler, S. A.: The impact of ozone lines on AMSU-B radiances, Geophys. Res. Lett., 31, L21108, doi:10.1029/2004GL021214, 2004.

Lahoz, W. A., Errera, Q., Swinbank, R., and Fonteyn, D.: Data assimilation of stratospheric constituents: a review, Atmos. Chem. Phys., 7, 5745-5773, 2007, http://www.atmos-chem-phys.net/7/5745/2007/.

Lefèvre, F., Brasseur, G. P., Folkins, I., Smith, A. K., and Simon, P.: Chemistry of the 1991-1992 stratospheric winter: Three dimensional simulations, J. Geophys. Res., 99, 8183-8195, 1994.

Massart, S., Piacentini, A., Cariolle, D., El Amraoui, L., and Semane, N.: Assessment of the quality of the ozone measurements from the Odin/SMR instrument using data assimilation, Can. J. Phys., 85(11), 1209-1223, 2007.

Parrish, D. and Derber, J.: The National Meteorological Centers spectral statistical interpolation analysis system, Mon. Weather. Rev., 120, 1747-1763, 1992.

Peuch, V.-H, Amodei, M., Barthet, T., Cathala, M. L., Josse, B., Michou, M., and Simon, P.: MOCAGE, MOdèle de Chimie Atmosphérique à Grande Echelle, In Proceedings of Météo-France: Workshop on atmospheric modelling, 33-36, December 1999, 1999.
Peuch, A., Thépaut, J.-N., and Pailleux, J.: Dynamical impact of total-ozone observations in a four dimensional variational assimilation, Q. J. Roy. Meteor. Soc., 126, 1641-1659, 2000.

Rabier, F., Järvinen, H., Klinker, E., Mahfouf, J.-F., and Simmons, A.: The ECMWF operational implementation of four dimensional variational assimilation. Part I: Experimental results with simplified physics, Q. J. Roy. Meteor. Soc., 126, 1143-1170, 2000.

Rasch, P. J. and Williamson, D. L.: On shape-preserving interpolation and semi-Lagrangian transport, SIAM J. Sci. Stat. Comput., 11, 656-686, 1990.

Rodgers, C. D.: Inverse methods for atmospheres: theories and practice, World Scientific Publ., Singapore, 2000.

Riishøjgaard, L. P.: On four-dimensional variational assimilation of ozone data in weather-prediction models, Q. J. Roy. Meteor. Soc., 122, 1545-1571, 1996.

Reed, R. J.: The role of vertical motions in ozone-weather relationships, J. Meteorol., 7, 263-267, 1950.

Rouil, L., Honoré, C., Vautard, R., Beekmann, M., Bessagnet, B., Malherbe, L., Meleux, F., Dufour, A., Elichegaray, C., Flaud, J.M., Menut, L., Martin, D., Peuch, A., Peuch, V.-H., and Poisson, N.: PREV'AIR: an operational forecasting and mapping system for air quality in Europe, B. Am. Meteorol. Soc., 90(1), 73-83, 2009.

Semane, N., Teitelbaum, H., and Basdevant, C.: A very deep ozone minihole in the Northern Hemisphere Stratosphere at midlatitudes during the winter of 2000, Tellus, 54A, 382-389, 2002.

Semane, N., Peuch, V.-H., El Amraoui, L., Bencherif, H., Massart, S., Cariolle, D., Attié, J.-L., and Abida, R.: An observed and analysed stratospheric ozone intrusion over the high Canadian Arctic UTLS region during the summer of 2003, Q. J. Roy. Meteor. Soc., 133(S2), 171-178, 2007.

Stajner, I., Wargan, K., Pawson, S, Hayashi, H., Chang, L. P., Hudman, R. C., Froidevaux, L., Livesey, N., Levelt, P. F., Thompson, A. M., Tarasick, D. W., Stuebi, R., Anderson, S. B., Yela, M., Koenig-Langlo, G., Schmidlin, F. J., and Witte, J. C.: Assimilated ozone from EOS-Aura: Evaluation of the tropopause region and tropospheric columns, J. Geophys. Res., 113, D16S32, doi:10.1029/2007JD008863, 2008.

Stockwell, W. R., Kirchner, F., Kuhn, M., and Seefeld, S.: A new mechanism for regional atmospheric chemistry modelling, J. Geophys. Res., 102, D22, 25 847-25 879, 1997.

Waters, J. W., Froidevaux, L., Harwood, R. S., et al.: The Earth Observing System Microwave Limb Sounder (EOS MLS) on the Aura satellite, IEEE T. Geosci. Remote Sens., 44, 1075-1092, 2006. 